\title{
The Creative Self-Concept as a Mediator Between Openness to Experience and Creative Behaviour*
}

\author{
Bin-Bin Chen \\ Fudan University, China \\ E-mail address: chenbinbin@fudan.edu.cn
}

\section{ARTICLE INFO}

\section{Keywords:}

Openness to Experience

Creative behaviours

Creative self-concept

University students

Article history:

Received 11 June 2016

Received in revised form 14 October 2016

Accepted 20 October 2016

\author{
A B S TRACT
}

ISSN: 2354-0036

DOI: 10.1515/ctra-2016-0024

Research evidence has been accumulating in recent years indicating that personality traits are related to creativity (e.g., Feist, 1998, 2010; Jonason, Richardson, \& Potter, 2015; Silvia, Kaufman, Reiter-Palmon, \& Wigert, 2011). Among various dimensions of personality traits, Openness to Experience is often considered as the most central trait to induce creativity. A large body of literature has provided consistent evidence showing that Openness to Experience was associated with creativity across cultures (e.g., Chen, 2016; Furnham, Zhang, \& Chamorro-Premuzic, 2005; Soldz \& Vaillant, 1999). However, the findings about the relationships between other personality traits such as Extraversion (e.g., Furnham, Zhang, \& Chamorro-Premuzic, 2005; Wolfradt \& Pretz, 2001) and Conscientiousness (e.g., Silvia, Kaufman, Reiter-Palmon, \& Wigert, 2011; Wolfradt \& Pretz, 2001) and creativity are not consistent. Therefore, the present study focused on Openness to Experience in examining the associations between personality traits and creativity.

Openness to Experience is characterized by intellectual curiosity and aesthetic sensitivity, and it is closely related to a flexible cognitive processing when solving problems

\footnotetext{
" The author gratefully acknowledges the general support from the research fund of the School of Social Development and Public Policy at Fudan University.
} 
(McCrae, 1987). Ample studies have provided evidence for the link between Openness to Experience and creativity (Feist, 1998; Furnham, Zhang, \& Chamorro-Premuzic, 2005; King, Walker, \& Broyles, 1996; Martindale, 1989; Soldz \& Vaillant, 1999). However, there is a dearth of research on the mechanisms by which Openness to Experience relates to creativity. Specifically, the pathways through which Openness to Experience may facilitate creativity remain elusive. In the present study, we propose and test a mediation model in which Openness to Experience is indirectly related to creativity through creative self-concept.

Recent theoretical explanations have been offered to explain how personality is expected to relate to creative behaviours. Graziano and colleagues (1997) have proposed that the self-concept may serve as a mediating role that translates personality into goalrelated activities and behaviours. For example, they found that social self-concept mediated the relationships between extraversion and peer relations among adolescents (Graziano, Jensen-Campbell, \& Finch, 1997). Within the same framework, one way to conceptualize the link of Openness to Experience and creative behaviours is in terms of the creative self-concept. There is some suggestive evidence to show creative selfconcept may serve as a potential mediator in the relationship between other variables to creative behaviours (Gong, Huang, \& Farh, 2009; Shin \& Zhou, 2007). Similar predictions may be formulated with regard to creative self-concept and the hypothesis that it mediates the relationships between Openness to Experience and creative behaviours is tested in the current study.

To my knowledge, no study has so far examined the mediation effect of creative selfconcept on the relationships between personality (e.g., Openness to Experience) and creative behaviours. Only a few published studies have indicated the bivariate correlations between Openness to Experience, creative self-concept and creative behaviours. On the one hand, extant research has suggested that personality, as a biologically rooted and core characteristic, continuously influences self-concept as one of the surface characteristics (Asendorpf \& Van Aken, 2003). For example, Openness to Experience has been found to be related to artistic self-concept (Marsh, Trautwein, Lüdtke, Köller, \& Baumert, 2006). Furthermore, given that both creative personal identity and creative self-efficacy stem from viewing oneself as a creative individual, conceptually they are more relevant to creative self-concept (Karwowski, 2015; Karwowski, Lebuda, Wisniewska, \& Gralewski, 2013). Both of them may be considered as components of self-concept. Previous research has found that creative identity and self-efficacy had the strongest relationship to Openness to Experience as compared with other personality factors (Karwowski, Lebuda, Wisniewska, \& Gralewski, 2013). And a recent meta-analysis also further confirmed these relations (Karwowski \& Lebuda, 2015). 
On the other hand, the belief in one's own creative abilities may exert its influence on people's behavioural tendencies or actual behavioural engagement in creative activities and tasks (Bandura, 1997; Furnham, Zhang, \& Chamorro-Premuzic, 2005). For example, consistent evidence has shown that creative self-efficacy, as one of the elements of creative self-concept (Karwowski, 2015), has an effect on creative behaviour in a qualitative study (Lemons, 2010), in workplace settings (Jaussi \& Randel, 2014; Tierney \& Farmer, 2011), in academic settings (Beghetto, Kaufman, \& Baxter, 2011)and in training programmes (Byrge \& Tang, 2015). This suggests that individuals use their beliefs about their personality traits when engaging in activities, so creative self-concepts play a role in creative behaviours (Silvia, Wigert, Reiter-Palmon, \& Kaufman, 2012).

Based on the preceding rationale and previous findings, it seems reasonable to hypothesize that the relationship between Openness to Experience and creative behaviours would be mediated by creative self-concepts. Specifically, Openness to Experience would be correlated with creative self-concepts which would in turn lead to an increase in creative behaviours. The model is presented in Figure 1. We tested the hypotheses by using structural equation modelling.

\section{METHOD}

\section{Participants and Procedure}

The sample comprised a convenience sample of Chinese undergraduate students recruited from a university located in the Eastern region of China. Two hundred and two undergraduates (118 males, 84 females; mean age $=19.97$ years, $S D=1.10$ ) voluntarily took part in the study. Participants were asked to complete self-report scales. They were assured of their confidentiality and anonymity.

\section{Measures}

Openness to Experience. Openness to Experience was assessed by the subscale of Openness to Experience from the short-form HEXACO scale of personality (Ashton \& Lee, 2009). This instrument taps six major factors of personality including HonestyHumility, Emotionality, Extraversion, Agreeableness, Conscientiousness and Openness to Experience. Each trait is measured with 10 items in this instrument. Only the 10 items (e.g., "People have often told me that I have a good imagination"; "I like people who have unconventional views") from the Openness to Experience factor, containing the facet subscales labelled Aesthetic Appreciation, Inquisitiveness, Creativity and Unconventionality, were used in the present study. Previous research has shown that the instrument has satisfactory reliability and validity in a sample of Chinese undergraduates (Chen, 2016). Participants were asked to respond to these items using a 5-point Likert scale 
( 1 = "strongly disagree" to 5 = "strongly agree"). Higher scores indicated higher levels of tendency towards the Openness to Experience trait.

Creative Behaviour. Creative behaviour was measured using the Biographical Inventory of Creative Behaviors (BICB; Batey \& Furnham, 2008). Participants were asked to respond to 34 creative activities (e.g. write a short story, draw a picture and decorate a room) that they had done within the last year. They responded to each item using a binary Yes/No format. The instrument demonstrated satisfactory reliability and validity in previous research based on a Chinese sample (Chen, 2016). Cronbach's alpha was .94 in the current study.

Creative Self-Concept. The Revised Creativity Domain Questionnaire (CDQ-R; Kaufman \& Baer, 2004; Kaufman et al., 2010) was used to measure an individual's beliefs about his/her level of creativity in diverse domains (i.e., four domains: drama, maths/ science, arts and interaction). This scale has proved reliable and valid in previous studies to assess people's self-concept concerning their personal ability in terms of creativity (Silvia et al., 2012). Participants were asked "How creative would you rate yourself in. ...", and then given 21 items (e.g., algebra, literature, leadership and painting) to rate their level of creative ability on a 6 -point scale $(1=$ "Not at all creative" to 6 = "Extremely creative"). The questionnaire demonstrated satisfactory reliability and validity in a sample of Chinese undergraduates (Chen, 2016). Cronbach's alpha was .86 in the current study.

\section{RESULTS}

\section{Descriptive Analyses}

Descriptive statistics and correlations among the observed variables are provided in Table 1. All correlations were in the expected direction. Openness to Experience was correlated with both creative behaviour and creative self-concept. Also creative behaviour and creative self-concept were correlated with each other.

Table 1

Descriptive statistics and correlations among the observed variables

\begin{tabular}{llll}
\hline Variables & 1 & 2 & 3 \\
\hline 1. Openness to Experience & - & & \\
2. Creative behaviour & $.30^{* * *}$ & - & \\
3. Creative self-concept & $.53^{* * *}$ & $.39^{* * *}$ & - \\
\hline$M$ & 3.22 & 9.52 & 3.24 \\
SD & .60 & 9.17 & .82 \\
\hline
\end{tabular}

Note. ${ }^{* * *} p<.001$ 


\section{Main Analyses}

To test the relationships among Openness to Experience, creative self-concept, and creative behaviour, Structural Equation Modelling (SEM) was conducted using Mplus 7.0 (Muthén \& Muthén, 2012). Using SEM, we employed the multiple-indicator approach to measure the three latent constructs. We used four facet subscales to measure the Openness to Experience construct. We also used four domains (i.e., drama, maths/science, arts, and interaction) of the Revised Creativity Domain Questionnaire to measure the creative self-concept construct. We applied the parcelling approach (Little, Cunningham, Shahar, \& Widaman, 2002) to create multiple indicators from the Biographical Inventory of Creative Behaviors to measure the creative behaviour construct. Two 8-item and two 9-item parcels were randomly formed as multiple indicators of the creative behaviour construct. Maximum likelihood estimation with robust standard errors was used in the SEM analysis. We relied both on the overall model fitness statistics and significance tests of specific paths to examine the direct association between Openness to Experience and creative behaviour and the indirect association between these two constructs through the mediation of creative self-concept.

The structural model, reported in Figure 1 , had satisfactory goodness of fit $\left(\chi^{2}(51\right.$, $N=202)=113.43, p<.05, \mathrm{CFI}=.95, \mathrm{RMSEA}=.08, \mathrm{SRMR}=.05)$. Although the chisquare test was significant, the chi-square to degrees of freedom ratio $\left(\chi^{2} / \mathrm{df}=2.22\right)$ was adequate according to the more stringent criterion of below 3.0 (Kline, 1998). We used the Sobel (1982) procedure to compute and test the indirect association between Openness to Experience and creative behaviour. It was statistically significant $(\beta=.31, p<.05)$. The mediating effect of creative self-concept proposed in the hypothesis was supported (see Figure 1). It indicated that Openness to Experience was related to creative selfconcept $\left(\beta=.78^{1} ; p<.001\right)$, and creative self-concept was related to creative behaviour $(\beta=.40 ; p<.05)$. But the direct path between Openness to Experience and everyday creativity was not statistically significant $(\beta=.09 ; p=.59)$.

\footnotetext{
${ }^{1}$ Given the strong association between creative self-concept and Openness to Experience, one reviewer suggested I should provide CFA results showing the separateness of these measures. The two-factor confirmatory model in the current sample yielded an acceptable fit, $\chi^{2}(19)=56.66, p<.001, \mathrm{CFI}=.90$, and SRMR $=.05$. All indicators had significant (ps <.001) and moderate loadings on the latent factors ranging from .49 to .78 .
} 


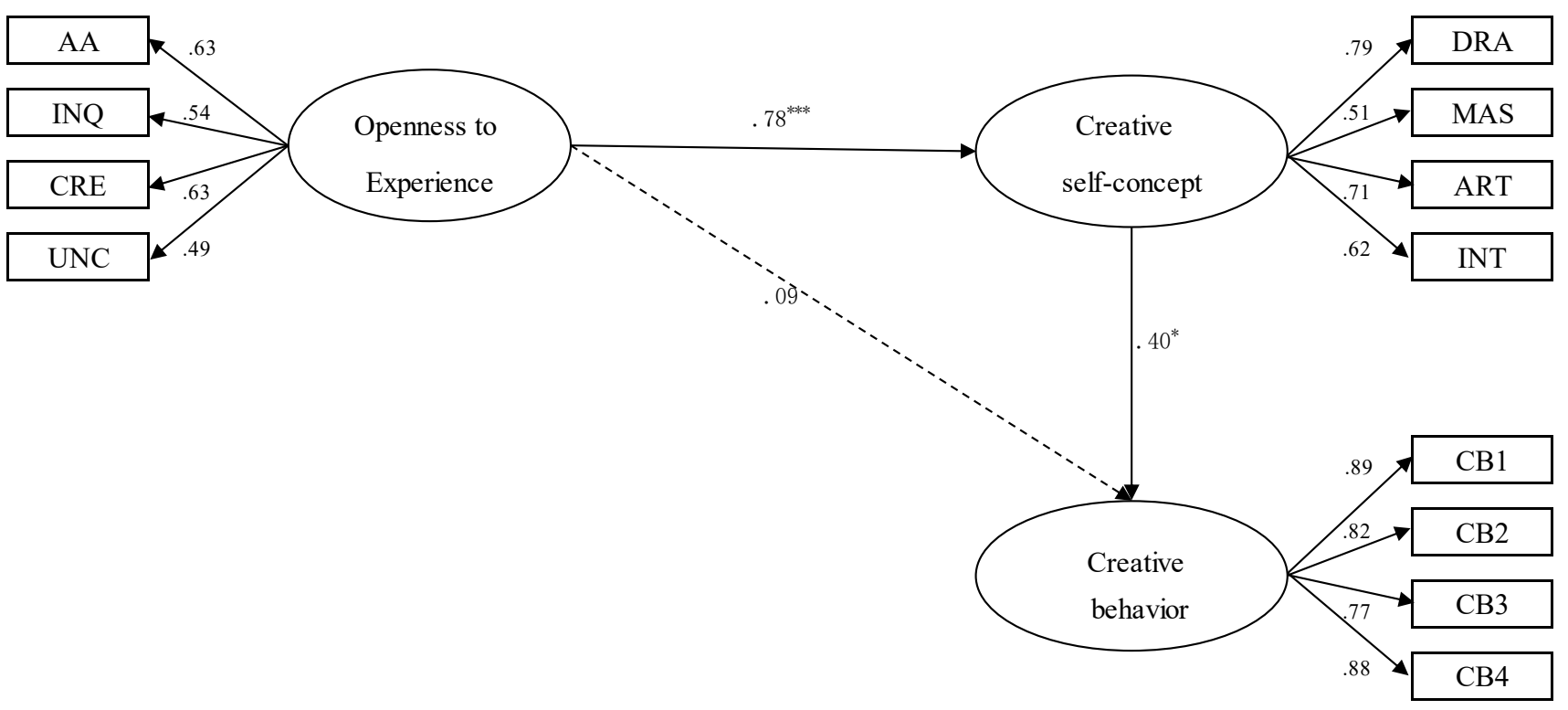

Figure 1. The model depicting the associations among Openness to Experience, creative self-concept, and creative behavior

Note. AA, INQ, CRE, and UNC: Aesthetic Appreciation, Inquisitiveness, Creativity, and Unconventionality subscales of the Openness to Experience Scale; DRA, MAS, ART, and INT: four domains (i.e., drama, maths/science, arts, and interaction) of creative self-concept construct; CB1 to 4: represent four item parcels from the Biographical Inventory of Creative Behaviors to measure creative behaviour. ${ }^{\star} p<.05 ;{ }^{* \star *} p<.001$.

\section{DISCUSSION}

This study is one of the first to examine the mediating effect of creative self-concept on the relationship between Openness to Experience and creative behaviours. In line with the hypotheses, the results showed that Openness to Experience was indirectly related to creative behaviours through creative self-concept. That is, people with higher levels of the Openness to Experience trait had a propensity to perceive themselves as creative, which may contribute to an increase in their level of creative behaviours. For researchers, this finding offers empirical evidence for one psychological mechanism by which personality contributes positively to creativity.

In addition, although the present study indicated Openness to Experience was correlated with both creative self-concept and creative behaviours in the bivariate correlations analysis, in the SEM, Openness to Experience was not significantly correlated with creative behaviours after introducing the mediator of creative self-concept. Also it should be noted that in the bivariate correlations analysis, Openness to Experience was strongly correlated with creative self-concept but moderately related to creative behaviours. Taken together, the present findings suggest that these relationships may be best described in terms of full mediation. The present study supports Graziano et al's (1997) theoretical model, whereby the self-concept may have a mediating role that translates personality 
into goal-related activities and behaviours. Our findings demonstrating this full mediation may further contribute to the existing literature.

Creative self-concepts may be interesting for practical reasons. People use their selfconcepts about their personality traits when engaging in a variety of activities (e.g., study tasks, job performances, hobbies and friendships). For example, to achieve the same task, people with different personality traits may go about it differently. People with Openness to Experience may have high levels of creative self-concepts, and hence they may produce creative thoughts on the task. On the contrary, people with Conscientiousness may lack creative self-concepts, but perhaps may have high levels of self-control and conformityrelevant self-concepts, and hence they may obey rules and conform to norms to compete the tasks without the addition of creative thoughts (Chen, 2016). In addition, creative selfconcept may serve an adaptive function especially when people encounter challenging situations where strong creative beliefs are necessary to enhance and maintain engagement in creative behaviours (Bandura, 1977). People with Openness to Experience have a belief in their own creativity and feel that being creative is an integral part of who they are, and finally reaffirm their creative identities through completing activities creatively.

The present study has limitations. Most notably, the correlational design limits causal interpretation, and self-report measures may create method variance. Although these are viable, widely used methods, future research would benefit from using longitudinal designs and multiple methods for evaluation. Another limitation of the present study is the inclusion of creative behaviours, with regard to the measures of creativity. An empirical question remaining for future research is whether the findings would hold using different measures of creativity. For example, including creative ability and performance as indicators would provide additional richness in the assessment of the associations addressed in the present study. Future research would also benefit from examining these associations in both workplace and study settings. Despite these and other limitations, this study extends previous research by providing preliminary support for the mediation effect of creative self-concept on the relationship between Openness to Experience and creative behaviours.

\section{REFERENCES}

Asendorpf, J. B., \& Van Aken, M. A. G. (2003). Personality-relationship transaction in adolescence: Core versus surface personality characteristics. Journal of Personality, 71, 629-666.

Ashton, M. C., \& Lee, K. (2009). The HEXACO-60: A short measure of the major dimensions of personality. Journal of Personality Assessment, 91, 340-345.

Bandura, A. (1977). Self-efficacy: Toward a unifying theory of behavioral change. Psychological Review, 84, 191-215. 
Bandura, A. (1997). Self-efficacy: The exercise of control. New York: Freeman.

Batey, M., \& Furnham, A. (2008). The relationship between measures of creativity and schizotypy. Personality and Individual Differences, 45, 816-821.

Beghetto, R. A., Kaufman, J. C., \& Baxter, J. (2011). Answering the unexpected questions: Exploring the relationship between students' creative self-efficacy and teacher ratings of creativity. Psychology of Aesthetics Creativity and the Arts, 5, 342-349.

Byrge, C., \& Tang, C. (2015). Embodied creativity training: Effects on creative selfefficacy and creative production. Thinking Skills and Creativity, 16, 51-61.

Chen, B.-B. (2016). Conscientiousness and everyday creativity among Chinese undergraduate students. Personality and Individual Differences, 102, 56-59.

Feist, G. J. (1998). A meta-analysis of personality in scientific and artistic creativity. Personality and Social Psychology Review, 2, 290-309.

Feist, G. J. (2010). The function of personality in creativity: The nature and nurture of the creative personality. In J. C. Kaufman \& R. J. Sternberg (Eds.), The Cambridge handbook of creativity (pp. 113-130). New York: Cambridge University Press.

Furnham, A., Zhang, J., \& Chamorro-Premuzic, T. (2005). The relationship between psychometric and self-estimated intelligence, creativity, personality and academic achievement. Imagination, Cognition and Personality, 25, 119-145.

Gong, Y., Huang, J.-C., \& Farh, J.-L. (2009). Employee learning orientation, transformational leadership, and employee creativity: The mediating role of employee creative self-efficacy. Academy of Management Journal, 52, 765-778.

Graziano, W. G., Jensen-Campbell, L. A., \& Finch, J. F. (1997). The self as a mediator between personality and adjustment. Journal of Personality and Social Psychology, 73, 392-404.

Jaussi, K. S., \& Randel, A. E. (2014). Where to look? Creative self-efficacy, knowledge retrieval, and incremental and radical creativity. Creativity Research Journal, 26, 400-410.

Jonason, P. K., Richardson, E. N., \& Potter, L. (2015). Self-reported creative ability and the Dark Triad traits: An exploratory study. Psychology of Aesthetics, Creativity, and the Arts, 9, 488-494.

Karwowski, M. (2015). Peer effect on students' creative self-concept. Journal of Creative Behavior, 49, 211-225.

Karwowski, M., \& Lebuda, I. (2015). The big five, the huge two, and creative self-beliefs: A meta-analysis. Psychology of Aesthetics, Creativity, and the Arts, Advance online publication. 
Karwowski, M., Lebuda, I., Wisniewska, E., \& Gralewski, J. (2013). Big five personality traits as the predictors of creative self-efficacy and creative personal identity: Does gender matter? Journal of Creative Behavior, 47, 215-232.

Kaufman, J. C., \& Baer, J. (2004). Sure, I'm creative - but not in mathematics!: Selfreported creativity in diverse domains. Empirical Studies of the Arts, 22, 143-155.

Kaufman, J. C., Waterstreet, M. A., Ailabouni, H. S., Whitcomb, H. J., Roe, A. K., \& Riggs, M. (2010). Personality and self-perceptions of creativity across domains. Imagination, Cognition and Personality, 29, 193-209.

King, L. A., Walker, L. M., \& Broyles, S. J. (1996). Creativity and the five-factor model. Journal of Research in Personality, 30, 189-203.

Kline, R. B. (1998). Principles and practice of structural equation modeling. New York: Guilford Press.

Lemons, G. (2010). Bar drinks, rugas, and gay pride parades: Is creative behavior a function of creative self-efficacy? Creativity Research Journal, 22, 151-161.

Little, T. D., Cunningham, W. A., Shahar, G., \& Widaman, K. F. (2002). To parcel or not to parcel: Exploring the question, weighing the merits. Structural Equation Modeling, 9, 151-173.

Marsh, H. W., Trautwein, U., Lüdtke, O., Köller, O., \& Baumert, J. (2006). Integration of multidimensional self-concept and core personality constructs: Construct validation and relations to well-being and achievement. Journal of Personality, 74, 403-456.

Martindale, C. (1989). Personality, situation, and creativity. In J. A. Glover, R. R. Ronning \& C. R. Reynolds (Eds.), Handbook of creativity (pp. 211-232). New York: Plenum Press.

McCrae, R. R. (1987). Creativity, divergent thinking, and openness to experience. Journal of Personality and Social Psychology, 52, 1258-1265.

Muthén, L. K., \& Muthén, B. O. (2012). Mplus user's guide (7th ed.). Los Angeles, CA: Muthén \& Muthén.

Shin, S. J., \& Zhou, J. (2007). When is educational specialization heterogeneity related to creativity in research and development teams? Transformational leadership as a moderator. Journal of Applied Psychology, 92, 1709-1721.

Silvia, P. J., Kaufman, J. C., Reiter-Palmon, R., \& Wigert, B. (2011). Cantankerous creativity: Honesty-Humility, Agreeableness, and the HEXACO structure of creative achievement. Personality and Individual Differences, 51, 687-689.

Silvia, P. J., Wigert, B., Reiter-Palmon, R., \& Kaufman, J. C. (2012). Assessing creativity with self-report scales: A review and empirical evaluation. Psychology of Aesthetics, Creativity, and the Arts, 6, 19-34. 
Sobel, M. E. (1982). Asymptotic confidence intervals for indirect effects in structural equation models. Sociological Methodology, 13, 290-312.

Soldz, S., \& Vaillant, G. E. (1999). The big five personality traits and the life course: A 45year longitudinal study. Journal of Research in Personality, 33, 208-232.

Tierney, P., \& Farmer, S. M. (2011). Creative self-efficacy development and creative performance over time. Journal of Applied Psychology, 96, 277-293.

Wolfradt, U., \& Pretz, J. E. (2001). Individual differences in creativity: Personality, story writing, and hobbies. European Journal of Personality, 15, 297-310.

Corresponding author at: Bin-Bin Chen, Department of Psychology, Fudan University, 220 Handan Road, Shanghai, 200433, China.

E-mail: chenbinbin@fudan.edu.cn 